\title{
TECNOLOGIAS PARA A PRODUÇÃo E PURIFICAÇÃo dO PVC
}

\author{
PRODUCTION AND PURIFICATION PVC TECHNOLOGIES
}

\author{
Rodrigo Ferreira Silva ${ }^{1}$; Luis Mário Nelson de Góis ${ }^{1}$ \\ ${ }^{1}$ Escola Politécnica, Universidade Federal da Bahia, Programa de Pós-Graduação em Engenharia Química. Rua Caetano \\ Moura s/n, Federação, Salvador, Brasil, CEP 40210-630. E-mail: rodrigoengquimico@ hotmail.com; lmario@ufba.br.
}

\begin{abstract}
RESUMO
O policloreto de vinila (PVC) é um dos mais importantes polímeros e pode ser produzido por alguns métodos, dentre os quais, a polimerização em emulsão, a polimerização em massa, a polimerização em solução e em suspensão. No processo de polimerização em suspensão, o mais utilizado, a conversão normalmente assume valores entre 83 e $90 \%$. Sendo assim, faz-se necessário uma posterior purificação com o objetivo de aumentar ainda mais a pureza da suspensão ou lama de PVC. Além disso, o cloreto de vinila é um agente cancerígeno. Várias técnicas são empregadas para reduzir o teor do monômero de cloreto de vinilo (MVC) no PVC produzido, sendo possível classificar essas técnicas em duas categorias. Na primeira, que envolve métodos químicos, o monômero não reagido é induzido a reagir, gerando novos compostos que devem apresentar uma maior facilidade de remoção e ser não tóxicos, ou, até mesmo, menos voláteis do que o MVC. Já na segunda categoria, constituída por métodos físicos, o MVC é retirado do PVC por volatilização ou por extração com um solvente, ou, ainda, com o auxílio de uma resina de troca iônica. O objetivo desta revisão é apresentar as principais tecnologias de produção e purificação de PVC, uma vez que tais tecnologias, em especial as de remoção do MVC, são pouco conhecidas e divulgadas principalmente por meio de patentes de modo superficial.
\end{abstract}

Palavras-chaves: Cloreto de vinila. Produção de PVC. Remoção de MVC.

\begin{abstract}
Polyvinyl chloride (PVC) is a major commercial polymer and is widely used as a raw material in various chemical and petrochemical products. PVC resins are made commercially by some processes like the suspension, emulsion, mass and solution process. The convertion in the suspension process is about 83 to 93 percent so, is required to removal the vinyl chloride monomer (VCM) from PVC resin. Moreover vinyl chloride is a cancer causing agent. Various techniques are employed for reducing the VCM content of the PVC, and these techniques can be classified into two categories. The first, chemical method, the unreacted monomer is induced to react by generating new compounds. These compounds must be easily removed, nontoxic or even less volatile than VCM. In the second category, on the other hand, the VCM is removed from PVC by physical methods like volatilization or extraction with a solvent, or it is removed with the aid of an ion-exchange resin. The aim of this review is to present the main PVC production and purification technologies since these technologies are currently known by only a few research groups and some project officers. Besides, informations about PVC, specially about PVC purification technology generally are disclosed through patents that address the topic superficially.
\end{abstract}

Keywords: Vinyl Chloride. PVC production. MVC remotion.

\section{INTRODUÇÃO}

Polímeros (do grego poly + meros $=$ muitas partes) são materiais de origem natural, artificial (polímeros naturais modificados) ou sintética, de natureza orgânica ou inorgânica, constituídos por muitas macromoléculas, possuindo cada uma dessas uma estrutura interna em que há a repetição de pequenas unidades (meros). 
Os monômeros são substâncias que constituem a matéria-prima para obtenção dos polímeros. O monômero é uma molécula simples, pelo menos bifuncional, ou seja, capaz de reagir por duas de suas terminações, que, em condições adequadas, dá origem à unidade de repetição (mero) das muitas cadeias poliméricas que formam o polímero. $\mathrm{O}$ monômero utilizado na polimerização do policloreto de vinila (PVC) é o monômero cloreto de vinila, e é daí que vem a origem da sigla MVC. Quanto à forma final de utilização, os polímeros podem ser divididos em plásticos, fibras poliméricas, borrachas (ou elastômeros), espumas, tintas e adesivos.

O termo "plástico", cujo significado é "moldável”, também deriva do grego. Os plásticos podem ser subdivididos em duas categorias, segundo seu comportamento tecnológico diante das condições de processamento: termoplásticos e termofixos. Os primeiros são materiais plásticos que apresentam a capacidade de ser repetidamente amolecidos pelo aumento de temperatura e endurecidos pelo resfriamento, sendo essa alteração, portanto, reversível (Junior; Nunes; Ormanji, 2006). O PVC, por exemplo, é considerado um termoplástico, uma vez que exibe essas características. Já os termofixos ou termorrígidos são materiais plásticos que, quando curados, com ou sem aquecimento, não podem ser reamolecidos por meio de um aquecimento posterior. O processo de cura consiste em uma série de reações químicas que promovem a formação de ligações primárias (ligações covalentes) entre as macromoléculas da resina termofixa, mediante o uso de calor, pressão, radiação ou catalisadores, tornando-a rígida, insolúvel e infusível.

O MVC é um gás incolor, inflamável e explosivo com uma pressão de vapor de $2530 \mathrm{mmHg}$ a $20^{\circ} \mathrm{C}$, e um ponto de ebulição de $-13,4^{\circ} \mathrm{C}$. Ele é pouco solúvel em água $\left(1,1 \mathrm{~g} / \mathrm{L}\right.$ a $\left.28^{\circ} \mathrm{C}\right)$, mas altamente solúvel em gorduras e solventes orgânicos. Sua polimerização ocorre na presença de luz e de catalisador e, quando sofre reação de combustão, é degradado a ácido clorídrico e dióxido de carbono.

\section{PRODUÇÃO DO PVC}

A produção do MVC é realizada por meio de duas rotas principais: a rota do eteno/cloro ou processo balanceado, que é a mais amplamente utilizada em escala mundial, e a rota do acetileno, que teve importância até meados da década de 1960, principalmente na Europa Ocidental. Apesar de a rota do acetileno apresentar a vantagem de menor custo de instalação da planta de produção, o custo do acetileno derivado do petróleo é maior que o do eteno, o que torna essa rota pouco viável economicamente. Entretanto, permanece como alternativa devido à possibilidade de obtenção do acetileno a partir de outras matérias-primas (Junior; Nunes; Ormanji, 2006).

Já na produção do PVC em escala industrial, são utilizados três processos principais: o da polimerização em suspensão (incluindo microssuspensão), o da emulsão e o em massa, sendo também empregado o processo de polimerização em solução, mas de maneira bastante limitada para o PVC. Esse último processo é utilizado, principalmente, para a produção de alguns copolímeros vinílicos, destinados, em especial, a tintas e vernizes.

Existe, ainda, conforme Georgiadou et al. (2009), uma técnica alternativa denominada de polimerização não aquosa, na qual é utilizado n-butano ou hexano como meio reacional. Os autores relatam, inclusive, que o polímero produzido mediante essa técnica apresenta maior porosidade, o que facilita a remoção do MVC não reagido em uma etapa posterior.

Da literatura, sabe-se, segundo Pereira (2005), que aproximadamente $80 \%$ do PVC consumido no mundo são produzidos por meio da polimerização do MVC em suspensão, ao passo que, pelos processos de polimerização em emulsão e microssuspensão, obtêm-se as resinas que são empregadas basicamente em compostos líquidos. Outros processos como a polimerização em massa e polimerização em solução possuem pouca representatividade no consumo total do PVC.

A vantagem da polimerização em suspensão é sua alta produtividade, flexibilidade quanto à composição do polímero e características das partículas. Além disso, a produção do PVC com a 
polimerização em suspensão proporciona uma variedade de produtos, cada qual com diferentes adequabilidades para certas operações (Junior, 1981).

No processo de polimerização em suspensão, o MVC é disperso na forma de gotas de diâmetro entre 50 e $250 \mu \mathrm{m}$ (Faria Junior, 2008), em meio a uma fase aquosa contínua, por agitação vigorosa e na presença de um colóide protetor, também chamado dispersante ou agente de suspensão. Um iniciador solúvel no monômero é utilizado, de modo que a reação de polimerização ocorra dentro das gotas em suspensão, por um mecanismo de reações em cadeia via radicais livres.

O carregamento dos reatores utilizados nesse processo, geralmente, é iniciado com água desmineralizada, aditivos de polimerização, dispersantes (na forma de solução) e iniciadores. Os reatores são, então, selados, e é utilizado alto vácuo para eliminar ao máximo o oxigênio do meio reacional, já que efeitos adversos podem acontecer no processo de polimerização, aumentando o tempo de reação e afetando as propriedades do produto final. Processado o vácuo no reator, faz-se a carga do MVC liquefeito e o aquecimento da camisa do reator com vapor sob pressão, para início da reação. Uma vez que a reação é iniciada, o reator deixa de ser aquecido e passa a ser resfriado, pois a reação é exotérmica, sendo a temperatura reativa o principal parâmetro para definição do peso molecular da resina, geralmente expresso pelo valor K (parâmetro utilizado na especificação da massa molar de um polímero).

Atingida a conversão da reação, geralmente na faixa entre 75 e $95 \%$, a reação é encerrada, e o monômero remanescente é recuperado. O polímero obtido na forma de lama (suspensão) passa, então, por um processo de stripping, no qual o MVC remanescente é extraído por meio de aplicação de vácuo e aumento de temperatura, tanto em reatores comuns quanto em torres, onde a lama é contatada com o vapor d'água em contracorrente. A lama passa, a seguir, por um processo de concentração via centrifugação, e o material úmido resultante é seco em secadores de leito fluidizado. A resina seca é, então, peneirada para retenção de partículas extremamente grosseiras e armazenada em silos, para posterior acondicionamento nos diferentes sistemas de distribuição, tais como sacaria de $25 \mathrm{~kg}$, grandes sacos de 1,2 t ou mais e, até mesmo, em caminhões-silo. A Figura 1 mostra um esquema simplificado do processo de polimerização em suspensão.

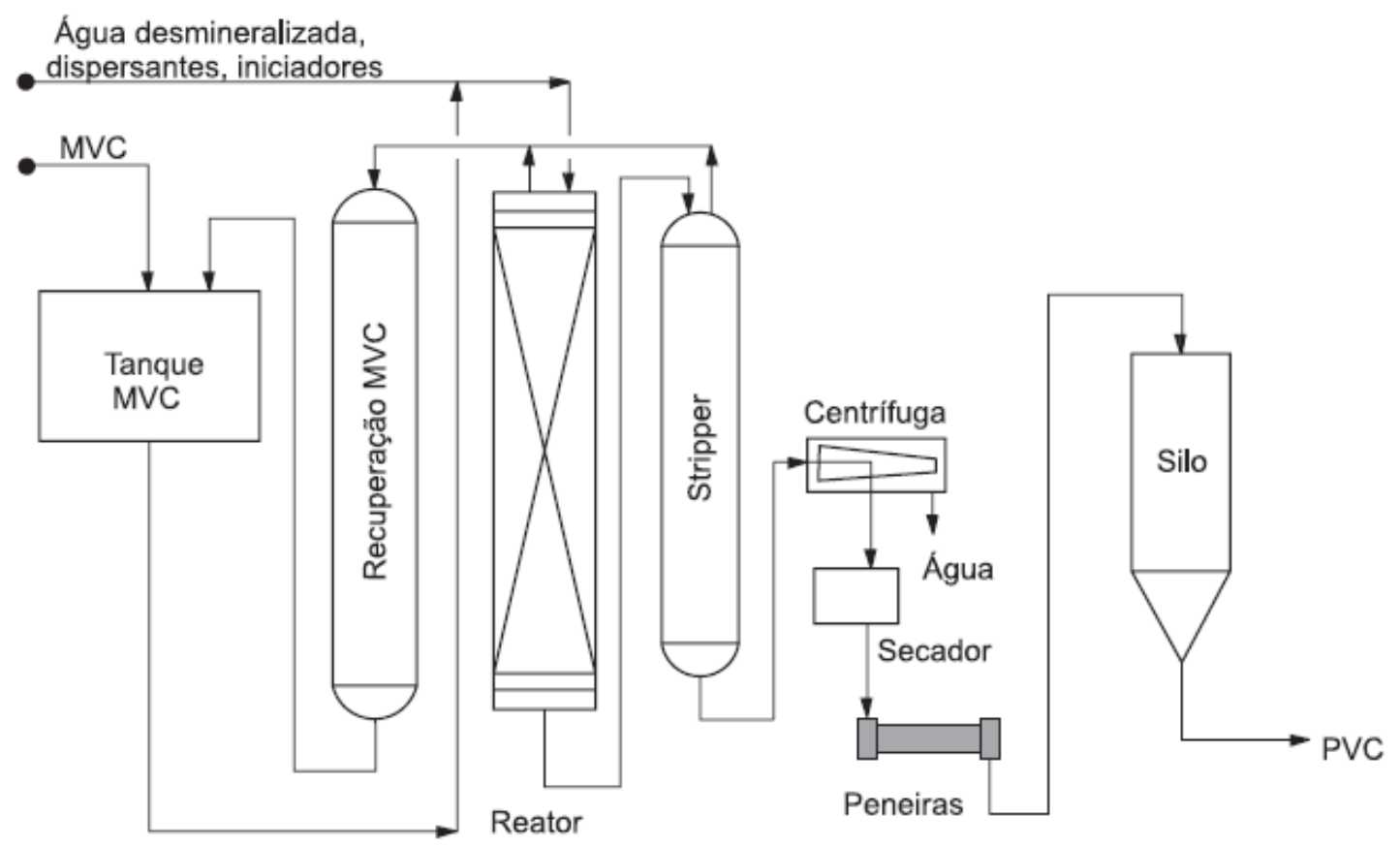

Figura 0: Representação esquemática do processo de polimerização em suspensão

Fonte: Junior; Nunes; Ormanji, 2006. 


\section{PROPRIEDADES DO PVC}

As principais propriedades do PVC são a densidade aparente, a porosidade e a granulometria. A seguir, essas propriedades serão descritas com maior detalhamento.

a) A densidade aparente (BD - Bulk density)

A densidade aparente de qualquer material, na forma de pó, é a relação da massa por unidade de volume desse material no estado não compactado. Tal propriedade é, portanto, importante na especificação da quantidade de resina que pode ser acomodada em determinado volume, sendo influenciada por parâmetros morfológicos, tais como tamanho e distribuição de tamanho de partícula, porosidade, formato e rugosidade superficial das partículas. A densidade aparente de resinas de PVC comerciais, geralmente, varia na faixa entre $0,45 \mathrm{~g} \cdot \mathrm{cm}^{-3}$ (resinas porosas para utilização em aplicações flexíveis) e $0,60 \mathrm{~g} . \mathrm{cm}^{-3}$ (resinas para aplicações em produtos rígidos transformados diretamente a partir do pó).

b) A porosidade

A porosidade pode ser definida como a razão entre o volume de vazios de um meio poroso e o volume total desse meio.

Existem três tipos de porosidade das partículas de PVC produzido via polimerização em suspensão: a porosidade entre partículas, a intrapartícula acessível e a intrapartícula inacessível.

A porosidade das resinas de PVC é um forte indicador da facilidade de remoção do MVC não reagido contido nas partículas, como também da capacidade de absorção de plastificantes. Esses aspectos são importantes nas aplicações de extrusão a sopro (garrafas e frascos), visto que esses produtos finais necessitam de uma boa transparência, baixo nível de pontos duros e de baixo nível de monômero não reagido, já que essas embalagens normalmente são utilizadas no acondicionamento de produtos alimentícios, óleos e cremes vegetais, água mineral etc.

c) A distribuição de tamanho das partículas

A granulometria, ou análise granulométrica, é o método mais simples de determinação da distribuição de tamanho de partícula, na qual é realizado o peneiramento da resina em malhas previamente selecionadas. Para garantir resultados mais confiáveis, o conjunto de peneiras e o recipiente coletor são montados em um dispositivo de agitação do sistema por batimento ou vibração intensa. Uma vez que as resinas podem passar a formar cargas estáticas, incorpora-se uma pequena quantidade de sílica ultrafina, a qual age como dissipador. Outro fator importante a ser considerado é a quantidade de resina colocada no topo do conjunto de peneiras, uma vez que quantidades excessivas podem provocar tanto a passagem forçada de partículas grossas pelas peneiras, quanto impedir o fluxo normal de material entre as diversas malhas. Assim, a análise granulométrica deve ser realizada criteriosamente para que tais problemas não ocorram.

Com relação aos aspectos morfológicos, as resinas de PVC obtidas pelo processo de polimerização em suspensão consistem em partículas com diâmetro normalmente na faixa de 50 a 200 $\mu \mathrm{m}$ e com estrutura interna bastante complexa.

O PVC é considerado um polímero amorfo ou de baixa cristalinidade, variando o grau de cristalinidade conforme as condições de polimerização. Polímeros comerciais possuem cristalinidade da ordem de 8 a 10\%, mas, em condições especiais, é possível aumentar significativamente esse valor. Polímeros obtidos a $5^{\circ} \mathrm{C}$ apresentam cristalinidade da ordem de $15 \%$, ao passo que, se a polimerização for realizada a $-75^{\circ} \mathrm{C}$, a cristalinidade é de cerca de $30 \%$. A Tabela 1 apresenta um sumário das principais características que definem a morfologia do PVC obtido por polimerização em suspensão. 
Tabela 1: Sumário da morfologia do PVC obtido pelo processo de polimerização em suspensão

\begin{tabular}{|c|c|c|}
\hline Espécie & Ordem de grandeza & Descrição \\
\hline Gotas de monômero & $100 \mu \mathrm{m}$ de diâmetro & $\begin{array}{l}\text { Monômero disperso na fase aquosa } \\
\text { contínua durante a polimerização } \\
\text { em suspensão. }\end{array}$ \\
\hline Membrana pericelular & $0,01 \mu \mathrm{m}$ de espessura & $\begin{array}{l}\text { Membrana presente na interface } \\
\text { monômero-água, consistindo em } \\
\text { um copolímero grafitizado de PVC } \\
\text { no dispersante. }\end{array}$ \\
\hline Partículas & 100 um de diâmetro & $\begin{array}{l}\text { Pó de fluxo livre formado após a } \\
\text { polimerização. Uma partícula é } \\
\text { formada de aproximadamente } 1 \\
\text { milhão de partículas primárias. }\end{array}$ \\
\hline Membrana & $1 \mu \mathrm{m}$ de espessura & $\begin{array}{l}\text { Estrutura que separa as partículas } \\
\text { primárias do meio exterior, formada } \\
\text { pela precipitação de PVC sobre a } \\
\text { membrana pericelular. }\end{array}$ \\
\hline Partículas primárias & $1 \mu \mathrm{m}$ de diâmetro & $\begin{array}{l}\text { Formadas pela precipitação do } \\
\text { polímero a partir do monômero } \\
\text { durante a reação de polimerização. } \\
\text { Consistem em cerca e } 1 \text { bilhão de } \\
\text { moléculas de PVC. }\end{array}$ \\
\hline $\begin{array}{l}\text { Aglomerados de partículas } \\
\text { primárias }\end{array}$ & $10 \mu \mathrm{m}$ de diâmetro & $\begin{array}{l}\text { Formados durante a reação } \\
\text { polimerização pela } \\
\text { partículas primárias. }\end{array}$ \\
\hline Domínios & $0,1 \mu \mathrm{m}$ de diâmetro & $\begin{array}{l}\text { Formados a partir de condições } \\
\text { especiais (precipitação da fase } \\
\text { aquosa ou deformação a quente). }\end{array}$ \\
\hline Cristalinos & $\begin{array}{l}0,01 \mu \mathrm{m} \text { de } \\
\text { espaçamento }\end{array}$ & $\begin{array}{l}\text { Moléculas de PVC empacotadas em } \\
\text { meio à fase amorfa. }\end{array}$ \\
\hline Cristalinidade secundária & $\begin{array}{c}0,01 \mu \mathrm{m} \text { de } \\
\text { espaçamento }\end{array}$ & $\begin{array}{l}\text { Cristalinidade formada a partir da } \\
\text { fase amorfa e responsável pelo } \\
\text { processo de gelificação/fusão. }\end{array}$ \\
\hline
\end{tabular}

Fonte: Junior; Nunes; Ormanji, 2006.

\section{O MVC RESIDUAL}

O MVC é reconhecidamente um agente altamente cancerígeno, razão pela qual suas plantas de produção, assim como as de polimerização do PVC, atendem a normas rígidas de saúde ocupacional, mantendo os níveis de MVC constantemente monitorados e, principalmente, abaixo de limites definidos por legislação específica, de modo a garantir baixo risco de exposição dos trabalhadores desses locais. Tal como descrito em momento anterior, a conversão normalmente atingida na reação de polimerização varia entre 75 e $95 \%$, sendo o MVC não reagido recuperado em uma primeira etapa após a polimerização e, posteriormente, eliminado de maneira forçada por meio de stripping da lama de PVC com vapor.

O teor do MVC residual na resina de PVC é determinado, geralmente, por meio de técnicas de cromatografia gasosa, tal como descrito na norma ASTM D-3749. Esse método prescreve a técnica de cromatografia gasosa com headspace para remoção do MVC da resina antes da análise 
cromatográfica. Resinas com teores de MVC residual na faixa de partes por bilhão (ppb) são avaliadas por meio do método descrito na norma ASTM D-4443, mais sensível que a norma anterior (ASTM D3749).

A quantidade de MVC não reagido pode ser considerada, também, uma função direta das condições de polimerização, tratamento posterior da resina e, principalmente, porosidade. Ou seja, resinas mais porosas permitem a remoção do MVC não reagido com maior facilidade, enquanto resinas de baixa porosidade proporcionam uma maior dificuldade a essa remoção. Os resultados de ensaios são, ainda, sensíveis ao intervalo de tempo entre a produção da resina e a realização da análise, uma vez que, mesmo à temperatura ambiente, o MVC residual possui uma taxa característica de dessorção da resina.

As resinas comerciais apresentam teores de MVC residual inferiores a $1 \mathrm{ppm}$, em concordância com as exigências apontadas pelos órgãos responsáveis de diversos países, tais como o Food and Drug Administration (FDA), o órgão regulamentador de alimentos e fármacos nos Estados Unidos, e o Instituto Adolfo Lutz, no Brasil (Pereira, 2005).

Até o início da década de 1960, o MVC era considerado pouco tóxico e era usado como um aerosol em alguns países, em especial nos EUA e no Japão. No entanto, em meados da mesma década, foi observada a ocorrência de uma doença óssea chamada acrosteólise (AOL) em um número pequeno de operadores de uma planta de PVC, especialmente envolvidos com a limpeza de reatores de PVC. A AOL leva, normalmente, a uma degeneração do osso na ponta dos dedos. Esse fato foi o responsável pelo desenvolvimento de tecnologias de limpeza e de prevenção, como, por exemplo, a limpeza com água à alta pressão (Saeki; Emura, 2002).

Em 1974, a B. F. Goodrich reportou ao National Institute of Occupational Safety and Health (NIOSH) a descoberta de casos de angiossarcoma (ASL), uma forma muito rara de tumor no fígado, entre trabalhadores de suas plantas de PVC. Desde então, a possibilidade de relacionamento desse câncer raro com a exposição de operadores a altas concentrações de MVC tornou-se tema mais urgente da indústria mundial do PVC. A Tabela 2 apresenta tópicos de alguns problemas relacionados ao contato com o MVC.

Tabela 2: Tópicos sobre problemas causados pelo MVC e regulamentações

\begin{tabular}{c|c|l|c}
\hline \multicolumn{1}{c|}{ Ano } & Mês & \multicolumn{1}{|c}{ Problema e regulamentação } & Concentração (ppm) \\
\hline $1965-1969$ & & Detectada a acrosteólise (AOL) & \\
\hline 1973 & 01 & $\begin{array}{l}\text { *FDA: proibição de garrafas de PVC para bebidas } \\
\text { alcoólicas }\end{array}$ & $\begin{array}{l}\text { Registro de mortes de trabalhadores da B. F. Goodrich } \\
\text { por angiossarcoma (ASL) } \\
\text { FDA: proibição de spray com MVC gasoso } \\
1974\end{array}$ \\
\hline 12 & $\begin{array}{l}\text { OSHA: concentração de MVC em condições de } \\
\text { trabalho (regulamentação temporária) } \\
\text { OSHA: regulamentação final }\end{array}$ & 50 \\
\hline 1975 & 12 & $\begin{array}{l}\text { FDA: permissão de PVC rígido e semirrígido para } \\
\text { comida (proposta) } \\
\text { EPA: regulamentação da concentração de MVC em } \\
\text { pontos de descarga (proposta) } \\
\text { Ministério da Previdência (Japão): concentração de } \\
\text { MVC em embalagens de PVC para comida }\end{array}$ & 10 \\
\hline
\end{tabular}

*FDA - Food and Drug Administration - Fonte: Saeki; Emura, 2002. 
Com relação à regulamentação ocupacional relacionada aos trabalhadores envolvidos com a produção de PVC, Pereira (2005) cita a existência de um estudo epidêmico detalhado, o qual teve como resultado a determinação de um limite de exposição ao MVC para casos de angiossarcoma (ASL). Ainda conforme esse autor, a exposição ao monômero acumulada de 288 ppm/ano é o valor mínimo para ocorrência de ASL.

Além disso, segundo Saeki e Emura (2002), a regulamentação do MVC para condições de trabalho de outros países, além dos Estados Unidos, determina um valor entre 1 e 5 ppm.

\section{TECNOLOGIAS PARA A REMOÇÃO DE MVC DO PVC}

No estudo da remoção de MVC do PVC, a análise do ponto de vista de transferência de massa, ou seja, do comportamento da concentração do soluto, no caso, o MVC, com o tempo e a temperatura é de extrema relevância. Nesse contexto, Erbay e Bilgiç (1995) apresentaram, em seu trabalho, as características da difusão do MVC no PVC, em condições semelhantes às industriais. Para tal, foram preparadas resinas com porosidades diferentes, por polimerização em suspensão, sendo as taxas de esgotamento do MVC investigadas sob uma temperatura correspondente à de ebulição da água para uma dada pressão.

Os autores citados mostraram que existe uma relação entre o coeficiente de difusão D do PVC e a temperatura que pode ser aproximada a uma expressão do tipo Arrhenius. Assim, segundo Erbay e Bilgiç (1995), a relação entre o coeficiente de difusão e a temperatura pode ser expressa da seguinte forma:

$$
\mathrm{D}=\mathrm{D}_{\infty} \exp \left(-\mathrm{E}_{\mathrm{D}} / \mathrm{RT}\right)
$$

onde $E_{D}$ é a energia de ativação aparente da difusão, ou seja, a energia por mol que uma molécula necessita para superar as forças atrativas que a prende em suas vizinhanças.

Ainda nesse mesmo trabalho, Erbay e Bilgiç (1995) encontraram para temperaturas entre $80^{\circ} \mathrm{C} \mathrm{e}$ $100^{\circ} \mathrm{C}$ uma energia de ativação igual a $36 \mathrm{~kJ} / \mathrm{mol}$, sendo esse resultado restrito à faixa de temperatura estudada pelos autores e para o tipo de PVC produzido e utilizado em seus experimentos.

Com o objetivo de descrever a remoção de MVC do PVC, Patel et al. (1979) propuseram um modelo que considera a transferência de massa como consequência de um gradiente de concentração entre a resina e o meio, sendo ele o seguinte:

$$
\frac{\mathrm{dC}_{\mathrm{s}}}{\mathrm{dt}}=-\mathrm{k}\left(\mathrm{C}_{\mathrm{s}}-\mathrm{C}_{\mathrm{m}}\right)
$$

onde

$\mathrm{C}_{\mathrm{s}}=$ concentração de MVC na partícula;

$\mathrm{C}_{\mathrm{m}}=$ concentração de MVC no meio;

$\mathrm{k}=$ constante de decaimento da concentração de MVC na partícula;

$\mathrm{t}=$ tempo.

Utilizando dados obtidos experimentalmente, Patel et al. (1979) determinaram a constante de decaimento, k, da concentração de MVC em resinas de PVC, a partir de curvas do tipo concentração de MVC na resina versus o tempo. Nesse trabalho, foi verificado que, para uma mesma resina, $\mathrm{k}$ é 
função da temperatura e da concentração de MVC na partícula. Além disso, a sua retirada é efetuada de forma mais rápida com água do que com ar.

No processo de produção do PVC, o monômero utilizado, ou seja, o MVC, não é convertido totalmente, sendo necessária uma remoção adicional. Até o início dos anos 1970, o MVC não reagido era removido por vácuo, sem aquecimento da lama, sendo o processo realizado em batelada. Como resultado, o teor de MVC residual na lama ficava entre 2.000 e 5.000 ppm.

Atualmente, para atender à legislação ambiental, as indústrias que utilizam esse processo introduzem a etapa de aquecimento da lama no pós-tratamento (etapa posterior à reação). Contudo, esse aquecimento ainda não consegue remover o MVC de forma a atingir os valores desejados, pois isso requer temperaturas e tempos elevados de tratamento, o que acarreta perda na qualidade da resina (degradação) e menor produtividade das plantas industriais.

Várias técnicas são empregadas para reduzir o teor do MVC no PVC produzido, sendo possível classificar esses processos em duas categorias. A primeira envolve métodos químicos, por meio dos quais o monômero não reagido é induzido a reagir, gerando novos compostos que devem apresentar uma maior facilidade de remoção, serem não tóxicos, ou, até mesmo, menos voláteis do que o MVC. Já na segunda categoria, constituída por procedimentos físicos, o MVC é retirado do PVC por volatilização ou por extração com um solvente, ou, ainda, com o auxílio de uma resina de troca iônica (Araújo et al., 2002).

As técnicas da primeira categoria são as seguintes:

a)Uso de iniciador: a apropriada seleção e adição do iniciador, ou do killer (substância empregada para interromper a reação), podem reduzir o tempo de reação, ou, ainda, exaurir o MVC não reagido após altas conversões do monômero serem atingidas;

b)Uso de um comonômero reativo: o MVC não reagido pode ser reduzido com a introdução, no final da reação, de um comonômero mais reativo;

c)Reação química: compostos apropriados podem ser usados para reagirem com o MVC por meio da dupla ligação existente;

d)Uso de radiação: a radiação eletromagnética, o uso de $\mathrm{Co}^{60}$ ou $\mathrm{Cs}^{137}$ como fontes de radiação, os aceleradores de elétrons e a radiação UV são também empregados para a redução do monômero (reação fotocatalisada).

Os métodos físicos, por sua vez, são os seguintes:

e)Aumento de temperatura: as constantes de propagação e os coeficientes de difusão aumentam com a temperatura, favorecendo uma conversão mais rápida do MVC não reagido. Contudo, várias desvantagens técnicas podem acompanhar um aumento de temperatura;

f)Desvolatilização do monômero não reagido: nesse caso, muitas técnicas podem ser empregadas, tais como o uso de baixas pressões (vácuo), altas temperaturas, adição de solvente e a passagem de um gás/vapor de modo a carrear o monômero;

g)Uso de resina de troca iônica: uma resina de troca iônica pode ser usada para reter o monômero não reagido. 
Com relação à técnica que utiliza reações químicas, existem várias reações disponíveis para converter o MVC a outras espécies químicas. Contudo, muitas das reações são lentas e, frequentemente, geram produtos tóxicos ou que requerem técnicas de remoção ou descarte.

De acordo com Marshall e Parker (1998), a reação de ozonização, por exemplo, pode contornar os problemas encontrados na remoção do MVC, rápida e eficientemente, mesmo à temperatura ambiente, e, apesar de a presença do cloro na molécula do MVC reduzir a taxa de reação, comparado, por exemplo, com o etileno, a reação ainda é rápida quando cotejada à de outras olefinas substituídas.

A seguir, é mostrada a reação química de ozonização:

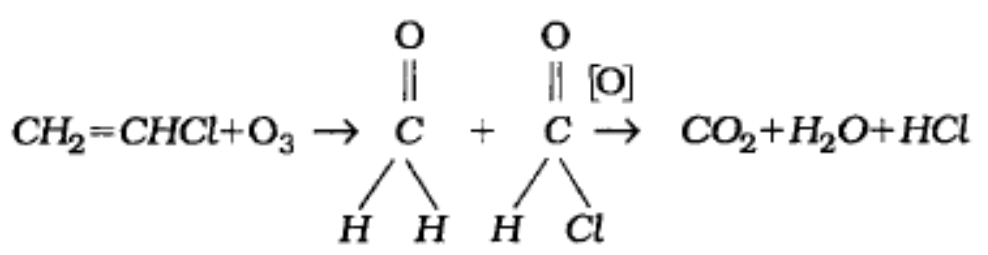

Reação 1: Ozonização do cloreto de vinila

Os produtos finais da reação de ozonização do MVC, mostrados na Reação 1, são totalmente inócuos, com exceção do ácido clorídrico, o qual pode ser neutralizado por agentes tamponantes presentes na mistura reacional.

No tocante ao uso de radiação para a remoção do MVC, Reilly (1986), em seu trabalho, descreveu a utilização de radiação de alta energia, tal como raios gama ou elétrons acelerados. Além disso, o autor cita a utilização de agentes químicos que auxiliam na proteção do polímero contra uma possível degradação, assim como na redução da concentração do monômero a níveis aceitáveis. Exemplos representativos de tais agentes são as olefinas ou diolefinas, tais como acrilato, estireno, isopreno e butadieno.

Na operação unitária esgotamento ou stripping, uma mistura líquida é posta em contato com um gás para que ocorra a remoção do(s) componente(s) da fase líquida para a fase gasosa. Essa operação é, geralmente, utilizada nos casos em que há uma diferença significativa de volatilidade entre os componentes de uma mistura líquida. No caso do stripping do PVC, recorre-se a uma técnica de desvolatilização em que a lama de PVC é submetida a temperaturas mais elevadas por curto período de tempo, em um processo contínuo. Isso minimiza a degradação térmica e a perda de produtividade na etapa do tratamento da lama.

O conceito de stripping do PVC não é novo, mas os avanços realizados pelas companhias envolvem equipamentos especializados compactos e know-how no aspecto operacional, que previne a degradação do PVC. O teor de MVC com o uso dessa tecnologia pode ser reduzido a menos de $1 \mathrm{ppm}$, e o processo pode ser totalmente automatizado, de forma a torná-lo uma opção atrativa às plantas de PVC já existentes.

As primeiras patentes que tratam do stripping de PVC surgiram nos anos 1970, época na qual ocorreram os primeiros estudos sobre essa tecnologia, por conta da detecção, na década anterior, de problemas ocupacionais causados pela exposição de trabalhadores ao MVC. Nesse contexto, surgiram, como alternativas tecnológicas, a coluna stripper, a atomização do látex de PVC, o aquecimento da suspensão de PVC sob condições de vácuo etc.

Dentre as patentes sobre o tema, a de Grosse-Wortmann et al., do ano de 1977, mostra que, para uma remoção satisfatória do MVC não reagido, é necessária uma combinação dos seguintes fatores: alta porosidade da resina, vazão de vapor e temperatura da lama adequadas.

A Figura 2, elaborada por Grosse-Wortmann et al. (1977), mostra curvas de esgotamento que relacionam a concentração de MVC com o tempo, para diferentes temperaturas e razões de vaporização (kg vapor/kg PVC). 

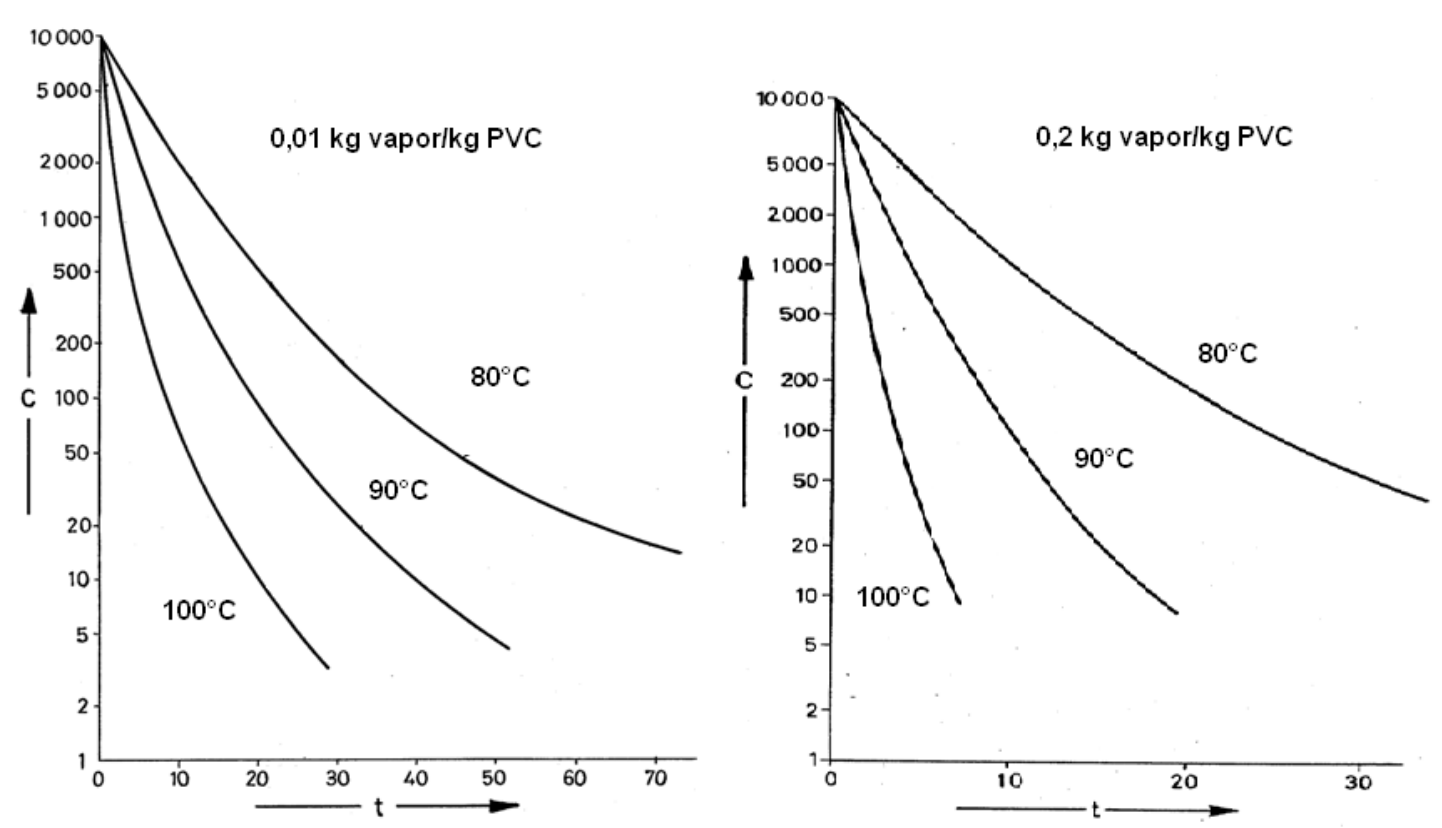

Figura 2: Curvas de esgotamento

Fonte: Grosse-Wortmann et al., 1977.

De acordo com os gráficos mostrados na Figura 2, os autores observaram que o aumento da temperatura da lama de PVC, associado com uma maior razão de vaporização, favorece a remoção do MVC, com uma significativa redução do tempo de operação.

Nessa mesma linha, Patel et al. (1977) relataram a atomização do látex de PVC, com uma concentração de MVC entre 1.000 a 5.000 ppm. Essa atomização, segundo os autores, ocorre sob condições de baixo cisalhamento, onde um fino spray de látex é submetido a condições de vácuo, possibilitando a saída do MVC não reagido. Após esse tratamento, o látex é adicionalmente processado, para gerar o produto sólido contendo uma concentração de MVC inferior a 10 ppm.

Cich et al. (1980) apresentaram um método para aumentar a taxa de remoção do MVC pela adição de depreciadores da temperatura de transição vítrea, $\mathrm{T}_{\mathrm{g}}$, do polímero. Nesse trabalho, os autores afirmam que qualquer material que reduz a $\mathrm{T}_{\mathrm{g}}$ do $\mathrm{PVC}$, sem degradar a resina, pode ser usado em combinação com altas temperaturas e pressões reduzidas.

Ainda segundo Cich et al. (1980), a eficiência da remoção do MVC varia com a escolha do depreciador da $\mathrm{T}_{\mathrm{g}}$, temperatura e nível de vácuo do sistema. Além disso, foi sugerido, nesse trabalho, que a concentração do depreciador de $\mathrm{T}_{\mathrm{g}}$ estivesse entre 0,05 a $2,5 \mathrm{~m} / \mathrm{m}$, sendo essa escolha baseada na efetividade do depreciador e sobre efeitos secundários, tais como as propriedades plastificantes desejadas. Cich et al. citam, como exemplos de depreciadores, o tolueno, o metano, o etano, o propanol, dentre outros.

Na patente apresentada por Hornbaker et al. (1978), está descrita uma alternativa tecnológica na qual a lama de PVC é agitada em um vaso, sendo vapor injetado diretamente de forma a aquecer a lama rapidamente a uma temperatura de pelo menos $82,2^{\circ} \mathrm{C}$. Em uma etapa posterior, a lama é resfriada ou estrategicamente mantida, por um período de tempo, a uma determinada temperatura e, então, rapidamente resfriada pela aplicação de vácuo ao vaso, para, em seguida, o vapor removido ser condensado. Conforme os autores, as resinas obtidas por meio desse processo possuem um teor de MVC abaixo do limite detectável de 0,5 ppm.

Hughes e Plainfield (1980) também observaram que o MVC pode ser removido de uma dispersão aquosa de PVC, porém, pelo contato com vapor d'água e acetato de vinila a uma temperatura não superior a $85^{\circ} \mathrm{C}$ e sob pressão subatmosférica, ocorrendo, nesse caso, a remoção de pelo menos $90 \%$ do MVC presente. Conforme os autores, a dispersão assim tratada conterá menos de 
$1 \mathrm{ppm}$ de MVC, podendo tal processo ocorrer em uma coluna, preferencialmente com pratos perfurados tipo dualflow, com 10 a 30 estágios.

Já Noël et al. (1980) sugeriram o esgotamento da lama de PVC em batelada, por meio do borbulhamento direto do vapor, baseados no fato de que é essencial manter a temperatura da lama no valor da temperatura de transição vítrea do polímero. Já com relação ao limite superior da temperatura sob a qual o esgotamento pode ocorrer, foi observado, nesse trabalho, que tal parâmetro é dado pela temperatura de degradação do polímero. Por questões de segurança, foi sugerido, também, o aquecimento da lama de PVC a uma temperatura não superior a $120^{\circ} \mathrm{C}$ com o objetivo de se obter um PVC não degradado. Com relação à pressão de operação da coluna, os autores recomendaram a operação sob a pressão de saturação da água quando o vapor é usado como fluido de esgotamento.

Além desses trabalhos, Goodman et al. (1980), em três patentes, trouxeram técnicas nas quais a lama, adicionada a compostos orgânicos e inorgânicos, é aspergida sob pressões subatmosféricas, enquanto Okada et al. (1985) indicaram a opção da utilização de colunas preenchidas com recheios tipo Tellerette, conforme mostra a Figura 3.

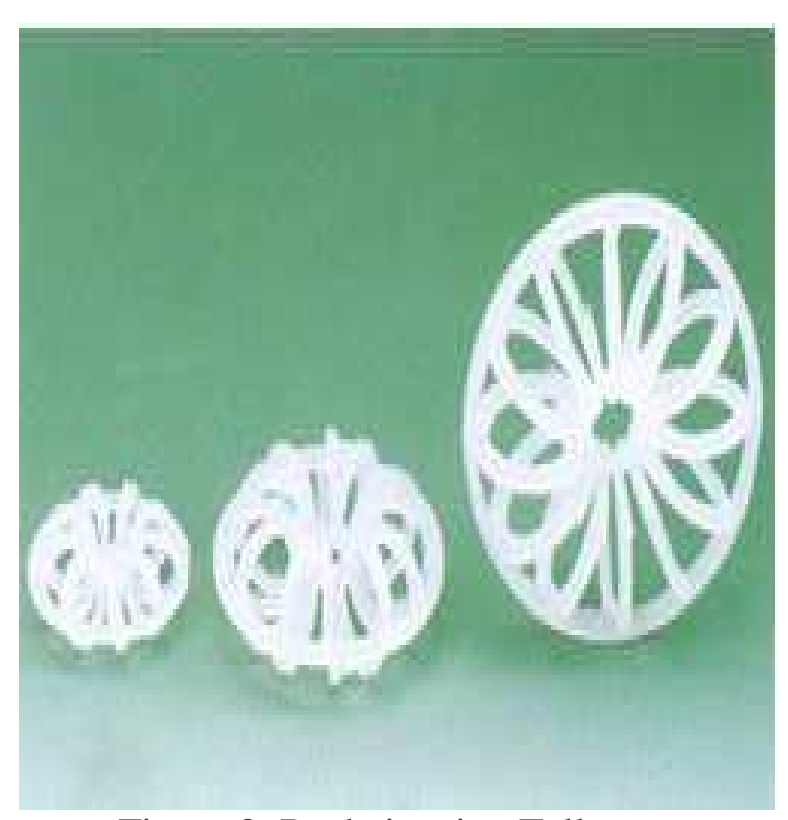

Figura 3: Recheios tipo Tellerette

Segundo Okada et al. (1985), o uso de colunas com recheios permite boa remoção de MVC, sendo, porém, observada, nesse caso, a formação de espuma na coluna. A solução encontrada para contornar tal problema, possibilitando boa eficiência, foi o acoplamento de um condensador ao topo da coluna experimental.

Por fim, Noël et al. (1980) constataram, igualmente, que o tempo de esgotamento não é função apenas da temperatura, mas também do teor de MVC na lama, do grau de pureza desejado e da porosidade das partículas do PVC.

\section{MODELAGEM MATEMÁTICA DAS COLUNAS STRIPPERS}

Os modelos matemáticos existentes na literatura, que representam uma coluna stripper, são baseados em balanços de massa e de energia, equações de equilíbrio ou em relações empíricas. Na literatura, existem vários algoritmos para a solução de sistema de equações resultante da modelagem prato a prato de processos de separação, dentre os quais, o método não rigoroso de Brooman e Brito 
(2005) modificado e um outro, rigoroso, o Sum-Rates (SR), ou Soma das Vazões aplicado ao sistema trifásico PVC/água/vapor (Silva, 2011).

\subsection{O método não rigoroso}

A abordagem não rigorosa para a modelagem de uma coluna em escala piloto segue a metodologia empregada por Brooman e Brito (2005) com algumas modificações, sendo utilizados, também, os dados de cinética de remoção de MVC do PVC obtidos por Patel et al. (1979), adaptados ao caso da coluna stripper.

Com relação a essa coluna, deve-se salientar que, do ponto de vista microscópico, stripping é um processo de transferência de massa, o qual pode ser representado, de modo simplificado, como mostra a Figura 4.

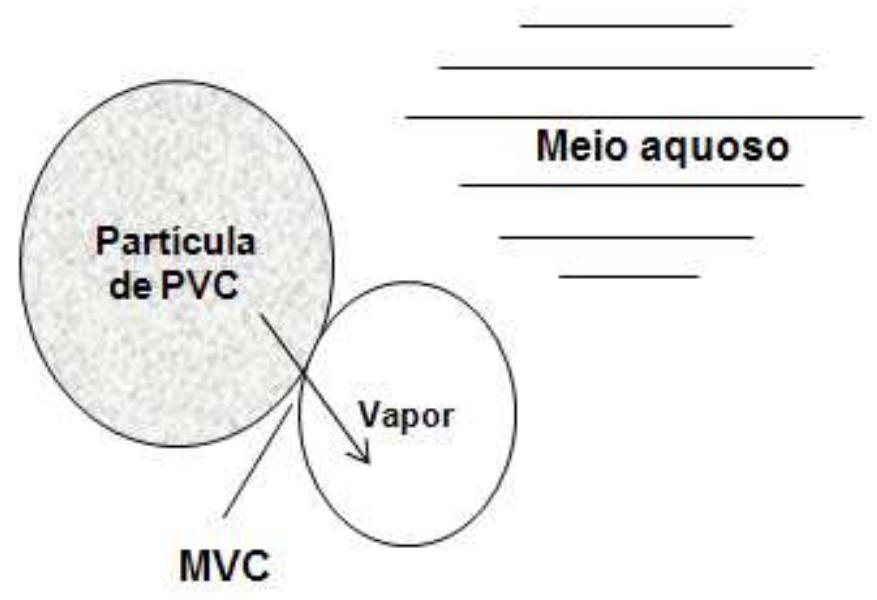

Figura 4: Ilustração da transferência de massa do MVC presente no PVC, para uma corrente de vapor

Ou seja, o MVC é retirado da partícula de PVC por meio do contato com o vapor d'água, o que caracteriza um processo de dessorção. Sendo assim, por conta da baixa solubilidade do MVC em água, que é em torno de $0,11 \mathrm{~g}$ MVC para cada $100 \mathrm{~g}$ de $\mathrm{H}_{2} \mathrm{O}$, pode-se considerar que a transferência de massa ocorre diretamente entre a partícula de PVC e a bolha de vapor.

\subsection{Metodologia sum-rates modificada}

O método sum-rates, descrito em Henley e Seader (2001), foi adaptado gerando uma nova abordagem baseada nas mesmas hipóteses do método anterior, sendo, ao contrário do que é mostrado pela Figura 4, considerada, também, a transferência de massa que ocorre entre a fase sólida e a fase líquida, ou seja, a transferência de massa (MVC) entre a partícula do PVC e a água, de modo a possibilitar um tratamento completo do fenômeno, que envolve, na verdade, um equilíbrio trifásico sólido/líquido/gás.

A idealização desse novo fenômeno é mostrada na Figura 5. 


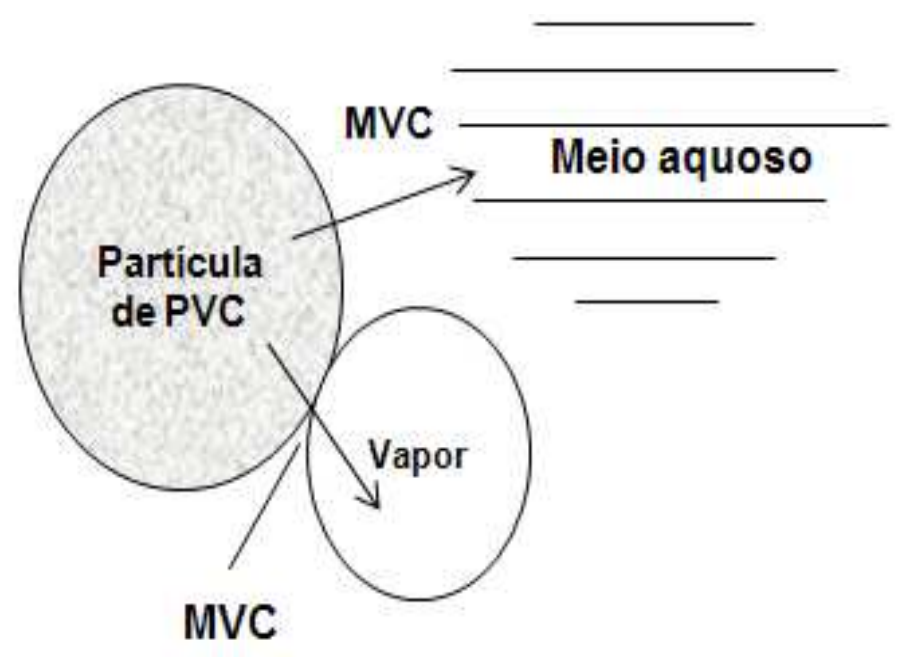

Figura 5: Ilustração do mecanismo de transferência de massa entre a partícula de PVC, o vapor e a água

Conforme já citado, os modelos que descrevem uma coluna stripper são, em geral, as equações de balanço de massa, de energia, as relações de equilíbrio e outros modelos empíricos. Contudo, ao contrário da metodologia anterior, a fração mássica do MVC nas correntes é igualmente considerada.

\section{CONCLUSÕES}

Conforme descrito nas seções acima, o que existe atualmente na literatura sobre a tecnologia de remoção de MVC da lama de PVC são equipamentos, principalmente colunas strippers, que visam a melhorar tal remoção, seja mediante o uso de vapor como agente de arraste, seja pela adição de substâncias químicas, ou pelo aumento da área de contato entre a lama e o agente de arraste. Com relação às condições operacionais, são utilizadas, de um modo geral, temperaturas entre $85^{\circ} \mathrm{C}$ e $120^{\circ} \mathrm{C}$ sob condição de vácuo, com a obtenção de concentrações de MVC entre 1 e 10 ppm.

Por fim, no que se refere ao estudo matemático, pode-se utilizar planejamento experimental e modelagem fenomenológica para a predição de parâmetros e, também, para a otimização das condições operacionais.

\section{AGRADECIMENTOS}

Ao Programa de Pós-Graduação em Engenharia Química da Universidade Federal da Bahia.

\section{REFERÊNCIAS}

ARAÚJO, P. H. H. et al. Techniques for reducing residual monomer content in polymer: a review. Polymer Engineering and Science, v. 42, n. 7, p. 1442-1468, 2002. 
BROOMAN, J. H.; BRITO, R. P. PVC stripping column modeling and simulation. In: ENPROMER, $2^{\circ}$ Mercosur congress on Chemical Engineering and $4^{\circ}$ Mercosur Congress on Process Systems Engineering, Rio de Janeiro, 2005.

CICH, F. A.; GLAZER, E. J.; SMITH, E. S. Method of removing vinyl chloride monomer from polyvinyl chloride resins. United States Patent, n. 4205149, 1980.

ERBAY, E.; BILGIÇ, T. Diffusion characteristics of vynil chloride from PVC in slurry phase. Die Angewandte Makromolekulare Chemie, v. 226, n. 3933, p. 39-46, 1995.

FARIA JUNIOR, J. M. Monitoramento in-situ e em tempo real de variáveis morfológicas do PVC com o uso de uma sonda NIR. 2008. Tese (Doutorado em Engenharia Química) - UFRJ/COPPE - Rio de Janeiro, 2008.

GEORGIADOU, S. et al. Nonaqueous polymerization of vinyl chloride: an environmentally friendly process. Journal of Applied Polymer Science, v. 112, p. 2472-2481, 2009.

GOODMAN, D. et al. Process for the removal of vinyl chloride from polyvinyl chloride latexes and slurries. United States Patent, n. 4226974, 1980.

GOODMAN, D. et al. Process for the removal of vinyl chloride from polyvinyl chloride dispersions and latexes. United States Patent, n. 4226975, 1980.

GOODMAN, D. et al. Process for the removal of vinyl chloride from polyvinyl chloride latexes and slurries with hydrocarbon compounds. United States Patent, n. 4226976, 1980.

GROSSE-WORTMANN, H. et al. Process for the removal of vinyl chloride from polyvinyl chloride dispersions. United States Patent, n. 4017445, 1977.

HENLEY, J. E.; SEADER, D. J. Equilibrium-Stage separation operations in chemical engineering. New York: John Wiley \& Sons, 2001.

HORNBAKER, E. D.; NUGENT JR., A.; LOECHELT, C. P. Steam stripping polyvinyl chloride resins. United States Patent, n. 4086414, 1978.

HUGHES, W.; PLAINFIELD, N. J. Process for the removal of vinyl chloride from aqueous dispersions of vinyl chloride resins. United States Patent, n. 4228273, 1980.

JUNIOR, A. R.; NUNES, L. R.; ORMANJI, W. Tecnologia do PVC. São Paulo: ProEditores Associados Ltda., 2006.

JUNIOR, R. N. W. Poly(vinyl chloride) processes and products. Environmental Health Perspectives, v. 41, p. 123-128, 1981.

MARSHALL, R. A.; PARKER, D. K. Chemical removal of residual monomer from polyvinyl chloride latices and slurries. Journal of Vinyl and Additive Technology, v. 4, n. 1, p. 39-44, 1998.

NOËL, S. et al. Process for removing residual vinyl chloride from vinyl chloride polymers in aqueous dispersion. United States Patent, n. 4197399, 1980. 
OKADA, H. et al. Monomeric vinyl chloride stripping tower. United States Patent, n. 4526656, 1985.

PATEL, C. B. et al. Stripping rates of vinyl chloride from PVC resin. Journal of Polymer Science: Polymer Chemistry Edition, v. 17, p. 3775-3779, 1979.

PATEL, P. J.; MIRINGOFF, W. Process for the removal of vinyl chloride from latexes containing polyvinyl chloride. United States Patent, n. 4031056, 1977.

PEREIRA, M. B. Dimensionamento, modelagem e simulação de uma coluna de stripping experimental para a remoção de monômero do PVC. 2005. Dissertação (Mestrado em Engenharia Química) - UFBA/Escola Politécnica - Salvador, 2005.

REILLY, P. J. Monomer removal from a polymer. United States Patent, n. 4585808, 1986.

SAEKI, Y.; EMURA, T. Technical progresses for PVC production. Progress in Polymer Science, v. 27, p. 2055-2131, 2002.

SILVA, R. F. Estudo da remoção de MVC de lama de PVC usando uma coluna stripper. 2011. Dissertação (Mestrado em Engenharia Química) - UFBA/Escola Politécnica - Salvador, 2011. 